\title{
Isolation and identification of Mycobacterium avium complex and other nontuberculosis mycobacteria from drinking-water in Basra governorate, Iraq
}

\author{
A.A. Al-Sulami, ${ }^{7}$ A.M.R. Al-Taee ${ }^{2}$ and Q.H. Wida'a ${ }^{7}$
}

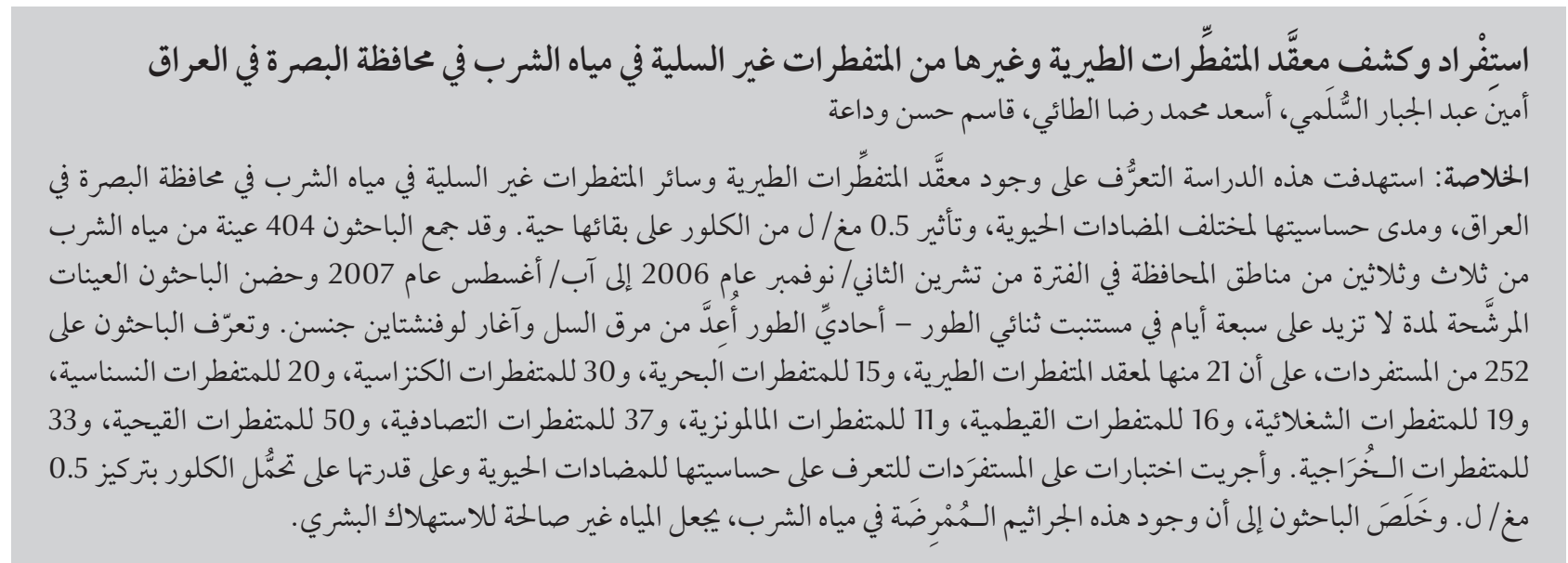

ABSTRACT This study aimed to determine the occurrence of Mycobacterium avium complex and other nontuberculous mycobacteria in drinking-water in Basra governorate, Iraq and their susceptibility to several antibiotics and the effect of $0.5 \mathrm{mg} / \mathrm{L}$ of chlorine on their survival. A total of 404 samples of drinking-water were collected from 33 different districts of the governorate from November 2006 to August 2007. Filtered samples were incubated for 7 days or less in a monophasic-biphasic culture setup of tuberculosis broth and Lowenstein-Jensen agar. The 252 isolates were identified as M. avium complex (21), M. marinum (15), M. kansasii (30), M. simiae (20), M. szulgai (19), M. xenopi (16), M. malmoense (11), M. fortuitum (37), M. chelonae (50) and M. abscessus (33). Isolates were tested for antibiotic susceptibility as well as their ability to tolerate chlorine at a concentration of $0.5 \mathrm{mg} / \mathrm{L}$. The presence of these pathogenic bacteria in drinking-water renders the water unfit for human consumption.

Isolement et identification du complexe Mycobacterium avium et de mycobactéries autres que celles responsables de la tuberculose dans l'eau de boisson du gouvernorat de Bassora (Iraq)

RÉSUMÉ La présente étude visait à déterminer l'occurrence du complexe Mycobacterium avium et de mycobactéries autres que celles responsables de la tuberculose dans l'eau de boisson du gouvernorat de Bassora (Iraq). Elle a aussi évalué leur sensibilité à plusieurs antibiotiques et l'effet de 0,5 mg/I de chlore sur leur survie. Au total, 404 échantillons d'eau de boisson ont été recueillis dans 33 districts différents du gouvernorat entre novembre 2006 et août 2007. Les échantillons filtrés ont été incubés pendant sept jours ou moins dans des milieux monophasique et biphasique comprenant un bouillon de bacilles tuberculeux et un milieu Löwenstein-Jensen. Les 252 isolats ont été identifiés comme étant le complexe M. avium (21), M. marinum (15), M. kansasii (30), M. simiae (20), M. szulgai (19), M. xenopi (16), M. malmoense (11), M. fortuitum (37), M. chelonae (50) et M. bscessus (33). Les isolats ont été analysés pour connaitre leur sensibilité aux antibiotiques ainsi que leur capacité à tolérer du chlore à une concentration de $0,5 \mathrm{mg} / \mathrm{l}$. La présence de ces bactéries pathogènes dans l'eau de boisson la rend impropre à la consommation humaine. 


\section{Introduction}

Mycobacterium avium complex (MAC) is one of the bacteria on the United States Environmental Protection Agency's (EPA) contaminant candidate list [1]. MAC and rapidly-growing mycobacteria such as $M$. abscessus, M. mucogenicum, M. chelonae and M. fortuitum can survive, persist, grow and colonize drinkingwater supply systems [2-4].

When there is no evidence of personto-person transmission, itcan be assumed that humans are infected with nontuberculous mycobacteria from environmental sources [5]. However, several studies have failed to identify nontuberculous mycobacteria in water samples, often because of unsuitable isolation techniques [6]. Different growth rates, growth requirements and sources of water samples (e.g. treated, surface or natural) are all variables that affect the choice of method used for identification. Because of the slow growth of these organisms, pretreatment methods are necessary to limit bacterial and fungal overgrowth before mycobacteria can be detected. Unfortunately, the pretreatment method chosen may also prevent the detection of certain species of mycobacteria and reduce the rate of positive samples and the number of colonies seen [7].

The present study examined samples of drinking-water from different districts in Basra governorate, Iraq, to determine the occurrence of MAC and other nontuberculous mycobacteria, as well as their susceptibility to several antibiotics and the effect of $0.5 \mathrm{mg} / \mathrm{L}$ of chlorine on their survival.

\section{Methods}

A total of 404 samples of drinking-water were collected randomly for the purpose of this study from 33 districts in Basra governorate were collected during the period October 2006 to August 2007.

The concentration of residual chlorine for each sample was measured using a chlorine meter (Lovibond 2000).

Aliquots of $250 \mathrm{~mL}$ from each sample were filtered by membrane filtration technique using $47 \mathrm{~mm}$ cellulose acetate filters with a nominal pore size of 0.45 $\mu \mathrm{m}$ (Sartorius). The filters were cultured using the monophasic-biphasic culture setup method [8]. This was a simple system in which a slant of LowensteinJensen agar (LJ) was prepared in testtubes (160 mm size), followed by the introduction of $2 \mathrm{~mL}$ of tuberculosis (TB) broth to cover the lower portion of the slant only. The lower portion of the test-tube represents a biphasic environment (a liquid phase in contact with solid one), while the upper portion is single phase (solid only). To cultivate and isolate mycobacteria the filters were inoculated in TB broth for $5 \mathrm{~min}$. with shaking, after which the TB broth medium was poured in the test-tubes containing the slant, mixed well and then tilted once or twice to cover the upper portion of the slant prior to incubation. The test-tubes were incubated aerobically at $37^{\circ} \mathrm{C}$ for 7 days.

The suspected isolated mycobacteria were identified using a battery of biochemical tests according to the methods of Holt et al. [9] and Harley and Prescott [10]: oxidase test, catalase test, nitrate reduction test, tween 80 hydrolysis, growth with $5 \% \mathrm{NaCl}$, growth on MacConkey agar without crystal violet, urease test, pigmentation test, arylsulfatase test, pyrazinamidase test and $\mathrm{H}_{2} \mathrm{~S}$ production.

Mycobacteria isolates were also tested for their antibiotic susceptibility according to Piddock [11] by using 10 antibiotic disks: rifampin, kanamycin, streptomycin, azithromycin, ciprofloxacin, tobramycin, cephalothin, pyrazinamide, isoniazid, ethambutol.

To determine their resistance to chlorine the Mycobacterium spp. isolates were exposed to $0.5 \mathrm{mg} / \mathrm{L}$ concentrations of chlorine over 4 different time periods (30,60, 90 and $120 \mathrm{~s})$ [12].

The data were analysed using simple descriptive methods.

\section{Results}

Of the 200 samples taken in the winter season 80 (53\%) were free of chlorine, compared with only 175 (87.5\%) of the 200 summer samples.

A total of 252 isolates were identified as Mycobacterium spp., based on their morphological and biochemical characteristics in the battery of tests (Table 1). We succeeded in isolating slow- and rapid-growing bacteria from 30 districts in Basra. The slow-growing bacteria included: photochromogens, identified as M. marinum, M. kansasii and M. simiae (comprising $25.8 \%$ of total isolates), scotochromogens, identified as M. szulgai ( $7.5 \%$ of total isolates) and nonphotochromogens, which included M. avium complex, M. xenopi and $M$. malmoense (19.1\% of total isolates). The rapid-growing bacteria included $M$. $a b$ scessus, $M$. chelonae and M. fortuitum and comprised $47.6 \%$ of total isolates.

Isolates of all the species were found in 30 districts of the governorate and during both winter and summer seasons at chlorine concentrations of $0-0.5 \mathrm{mg} / \mathrm{L}$, but not at $>0.5-1.0$ and > $1.0-2.0 \mathrm{mg} / \mathrm{L}$.

Antibiotic susceptibility results using the tables supplied by the manufacturer of the kits showed that 7 species were sensitive to rifampin while the 3 rapidgrowing bacteria species were resistant (Table 2). For kanamycin, erythromycin, cephalothin, tobramycin and streptomycin all species were sensitive or mildly sensitive. On the other hand $M$. kansasii and M. marinum showed resistance to pyrazinamide, while other species were sensitive or mildly sensitive. All species were sensitive to ciprofloxacin. M. marinum was resistant to isoniazid and $M$. malmoense was resistant to azithromycin.

Inactivation of Mycobacterium spp. isolates by chlorination showed that not all species of Mycobacterium were sensitive to chlorine at $0.5 \mathrm{mg} / \mathrm{L}$ as, with the exception of M. szulgai, log reduction did not exceed 1 even after 120s exposure (Table 3 ). 

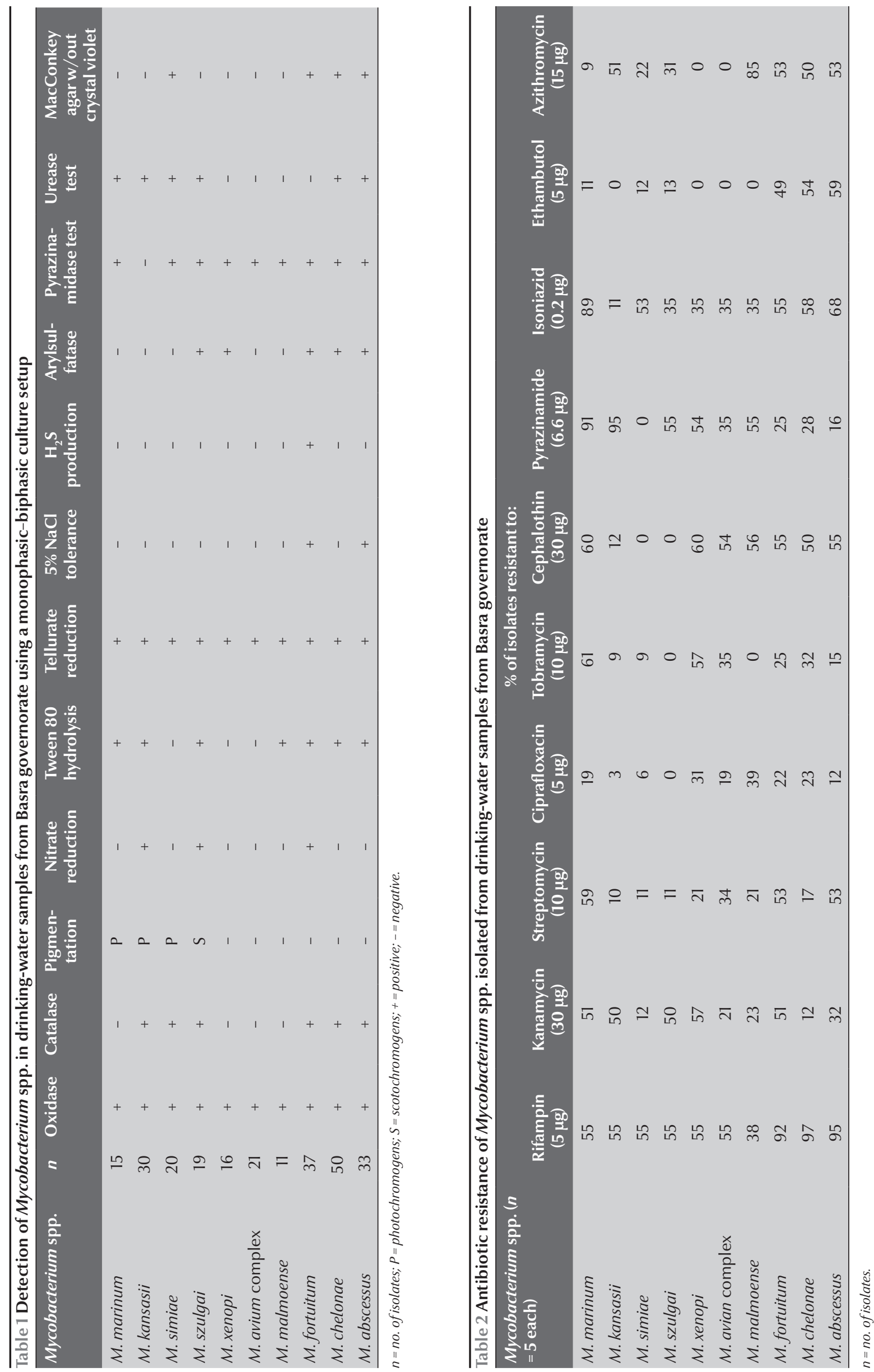


\section{Discussion}

The data confirm that members of the genus Mycobacterium are present in the drinking-water of Basra and the rate of recovery of MAC was $8.3 \%$ in the 252 mycobacterial isolates. Other species of mycobacteria were recovered in high numbers and this may be related to the method of isolation used in this study, i.e. the monophasic-biphasic culture setup. The EPA reported that the culture and isolation of MAC bacteria from environmental samples is problematic because of their slow growth (it can take months to see colonies on plates), the particular nutrient requirements and the presence of other microorganisms that quickly outgrow MAC [1].

There is a consensus in mycobacterial laboratories that at least 1 of the media used should be a broth-based and that the use of solid media alone is not optimal and is too slow compared with the rapid turnaround time in broth. A study of Lowenstein-Jensen media versus $7 \mathrm{H} 11$ biplates demonstrated recovery of mycobacteria of $40 \%$ and $80 \%$ respectively on these media [13]. The authors concluded that decisions about which broth system to use will depend on the needs of each laboratory and the performance of each system within any particular laboratory. The BACTEC
460 system is still considered the gold standard among broth cultures, if one can contend with the problems associated with use of radioactive materials [14]. A BACTEC instrument was not available to us, however, and other methods were too expensive or inconvenient to perform in our laboratory [15].

In the present study we succeeded in isolating mycobacteria from drinking-water using monophasic-biphasic culture, a method which has previously been used only for isolation of Mycobacterium tuberculosis from clinical specimens [16]. The monophasic-biphasic culture method allowed us to reduce the period of incubation to 7 days (or less in some cases) compared with typically 21-28 days in Lowenstein-Jensen medium. The efficiency of this method may be related to the simultaneous use of 2 types of media (solid and liquid) and its versatility for culturing a wide variety of mycobacteria. Monophasic-biphasic culture is also inexpensive because of the small quantities of liquid and solid media consumed, and in view of our results we suggest that the method is suitable for the isolation of mycobacteria from drinking-water in developing countries.

Antibiotic drug resistance in $\mathrm{Myco-}$ bacterium spp. is a worldwide problem [17]. A number of mechanisms for the resistance have been proposed, especially changes in the complex cell wall structure which contain mycolic acid and arabenogalactan in addition to peptidoglycan and which can reduce their permeability to antibiotics. For instance, isoniazid resistance has been associated with alterations in the inh $A$ gene, which encodes an enzyme that functions in mycolic acid synthesis, a component of the mycobacterial cell wall [18].

Resistance of Mycobacterium spp. to chlorine has been attributed to the growth of bacterial cells in the form of a biofilm that allows these bacteria to acquire greater resistance to disinfectants than free cells [19.]. Our conclusion from this study is that the ability of Mycobacterium spp. to survive in distribution systems may depend on factors such as the efficiency of disinfection process, as indicated by the very low chlorine concentration of $<$ $0.5 \mathrm{mg} / \mathrm{L}$ encountered in many districts of Basra.

The isolation of Mycobacterium spp. from drinking-water may depend on the techniques and materials used for culturing. It is noteworthy that $\mathrm{Myco-}$ bacterium spp. were isolated for the first time from municipal drinking-water supplies in Basra and we attribute this to the monophasic-biphasic culture method use in this study.

\begin{tabular}{|c|c|c|c|c|c|}
\hline \multirow[t]{2}{*}{ Mycobacterium spp. ( $n=5$ each) } & \multicolumn{5}{|c|}{ No. of $\log _{10}$ colonies present at different exposure times } \\
\hline & Control & $30 \mathrm{~s}$ & $60 \mathrm{~s}$ & $90 \mathrm{~s}$ & $120 \mathrm{~s}$ \\
\hline M. marinum & 9.477 & 9.301 & 9.146 & 8.954 & 8.698 \\
\hline M. kansasii & 9.462 & 9.301 & 9.146 & 8.954 & 8.602 \\
\hline M. simiae & 9.301 & 9.176 & 9.000 & 8.778 & 8.477 \\
\hline M. szulgai & 9.477 & 9.397 & 9.301 & 8.176 & 8.079 \\
\hline M. xenopi & 9.414 & 9.255 & 9.113 & 8.903 & 8.477 \\
\hline M. avium complex & 9.477 & 9.301 & 9.079 & 8.845 & 8.477 \\
\hline M. fortuitum & 9.477 & 9.342 & 9.204 & 9.000 & 8.845 \\
\hline M. chelonae & 9.431 & 9.301 & 9.146 & 8.954 & 8.968 \\
\hline M. abscessus & 9.477 & 9.301 & 9.179 & 9.000 & 8.968 \\
\hline M. malmoense & 9.477 & 9.301 & 9.176 & 9.000 & 8.968 \\
\hline
\end{tabular}

$n=$ no. of isolates. 


\section{References}

1. Regulatory determinations for priority contaminants on the second drinking-water contaminant candidate list. Washington DC, Environmental Protection Agency, 2008 (EPA report 815-R-08-012)

2. Williams MM et al. Structural analysis of biofilm formation by rapidly and slowly growing nontuberculous mycobacteria. Applied and Environmental Microbiology, 2009, 75:2091-2098.

3. Falkinham JD 3rd et al. Factors influencing numbers of $M y$ cobacterium avium, Mycobacterium intracellulare, and other mycobacteria in drinking-water distribution system. Applied and Environmental Microbiology, 2001, 67:1225-1231.

4. Torvinen E et al. Survival of Mycobacterium avium in drinkingwater biofilms as affected by water flow velocity, availability of phosphorus, and temperature. Applied and Environmental Microbiology, 2007, 73:6201-6207.

5. Covert TC et al. Occurrence of nontuberculous mycobacteria in environmental samples. Applied and Environmental Microbiology, 1999, 65:2492-2496.

6. Ford TT, Vincent V. Analytical methods for the detection of waterborne and environmental pathogenic mycobacteria. In: Pedly $\mathrm{S}$ et al. eds. Pathogenic mythobacteria in water, a guide to public health consequences, monitoring and management. London, IWA Publishing, 2004:55-73.

7. Thomson R et al. Comparison of methods for processing drinking-water samples for the isolation of Mycobacterium avium and Mycobacterium intracellulare. Applied and Environmental Microbiology, 2008, 74:3094-3098.

8. Al-Sulami A et al. A single step method for rapid isolation and identification of Mycoplasma pneumonia. Eastern Mediterranean Health Journal, 2002, 8:157-163.

9. Holt JG et al. Bergey's manual of determinative bacteriology. Baltimore, Williams and Wilkins, 1994:705-718.
10. Harley JP, Prescott LM. Laboratory exercises in microbiology, 3rd ed. Boston, McGraw-Hill, 1996:484.

11. Piddock LJJ. A review techniques use for the determination of antimicrobial resistance and sensitivity in bacteria. Applied Bacteriology, 1990, 68:307-318.

12. Johnson $\mathrm{CH}$ et al. Inactivation of Helicobacter pylori by chlorination. Applied and Environmental Microbiology, 1997, 63:49694970.

13. Wilson $\mathrm{ML}$ et al. Comparison of recovery rates for mycobacteria from BACTEC 12B vials, Middlebrook 7H-11 selective biplates and Lowenstein-Jensen slants in a public health mycobacteriology laboratory. Journal of Clinical Microbiology, 1995, 33:2516-2518.

14. Sewell DL et al. Comparison of the Septi-Chek AFB and BACTEC systems and conventional culture for recovery of mycobacteria. Journal of Clinical Microbiology, 1993, 31:2689-2691.

15. Flournoy D, Jeann JT. Modified Middlebrook 7H9 broth of the rapid detection of mycobacteria. Clinical Laboratory Science, 2001, 14:85.

16. Al-Sulami A et al. Rapid isolation and identification of $\mathrm{Myco-}$ bacterium tuberculosis from pulmonary tuberculosis patients. Asian Pacific Journal of Tropical Medicine, 2009, 2:70-73.

17. Raviglione A et al. Global epidemiology of tuberculosis. Journal of Clinical Microbiology, 1995, 32:110-114.

18. Brook GF et al. Medical microbiology, 21st ed. Lebanon, Typo Press, 1998.

19. Lechevallier MW, McFeters GA. Microbiology of activated carbon. In: McFeters G.A ed. Drinking-water microbiology, progress and recent developments. New York, Springer Verlag, 1988:104-119. 